\title{
Research Paper: Predicting Internet Addiction in Medical Students by General Self-efficacy, Difficulty in Emotion Regulation, and Resilience
}

\author{
Leila Salek Ebrahimi $^{1}$ (D), Gholamreza Ahmadi ${ }^{2}$,Abbas Masjedi Arani ${ }^{3}$, Seyedeh Elnaz Mousavi ${ }^{4^{*}}$ (D)
}

1. Research Center of Psychiatry and Behavioral Sciences, Faculty of Medicine, Tabriz University of Medical Sciences, Tabriz, Iran

2. Department of Psychology, Faculty of Psychology \& Educational Sciences, Allameh Tabatabaei University, Tehran, Iran.

3. Department of Clinical Psychology, School of Medicine, Shahid Beheshti University of Medical Sciences, Tehran, Iran.

4. Department of Clinical Psychology, School of Medicine, Zanjan University of Medical Sciences, Zanjan, Iran.

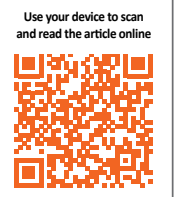

Crtation: Salek Ebrahimi, L., Ahmadi, Gh., Masjedi Arani, A., \& Mousavi, S. E. (2019). Predicting Internet Addiction in Medical Students by General Self-efficacy, Difficulty in Emotion Regulation, and Resilience. Journal of Practice in Clinical Psychology, 7(3), 167-174. http://dx.doi.org/10.32598/jpcp.7.3.167

doi http://dx.doi.org/10.32598/jpcp.7.3.167

(c) (1) (s)

Article info:

Received: 10 Dec 2018

Accepted: 05 Apr 2019

Available Online: 01 Jul 2019

Keywords:

Internet, Emotion, Social control, Self-efficacy

\section{A B S T R A C T}

Objective: The present study aimed to predict internet addiction based on general self-efficacy, difficulty in emotion regulation, and resilience in medical students.

Methods: This was a cross-sectional study. The statistical population included all medica students of Shahid Beheshti University of Medical Sciences. The research sample consisted of 96 medical students selected by random sampling method in 2018. Data collection was performed by Sherer General Self-Efficacy Scale, Gramat's and Roemer's Difficulties in Emotion Regulation Scale, Connor-Davidson Resilience Scale, and Young's Internet Addiction test.

Results: To analyze the obtained data, Pearson's correlation coefficient and the stepwise regression model were used. The obtained results suggested a significant relationship between internet addiction and general self-efficacy, difficulty in emotion regulation, and resiliency $(\mathrm{P}<0.05)$. Additionally, general self-efficacy, difficulty in emotion regulation, and resilience are able to predict $27 \%$ of internet addiction variance in medical students.

Conclusion: To prevent and reduce the harm of internet addiction in students in stressful events, they should be trained to improve their resilience, self-efficacy, and emotion regulation skills.

\section{* Corresponding Author:}

Seyedeh Elnaz Mousavi, PhD. Candidate

Address: Department of Clinical Psychology, School of Medicine, Zanjan University of Medical Sciences, Zanjan, Iran

Tel: +98 (910) 2033247

E-mail:elnaz48.mousavi@gmail.com 


\section{Highlights}

- The obtained results indicate a significant relationship between internet addiction and general self-efficacy, difficulty in emotion regulation, and resilience.

- General self-efficacy, difficulty in emotion regulation, and resilience can predict internet addiction in medical students.

\section{Plain Language Summary}

Official reports indicate that more than 56700000 internet users exist in Iran. The youth, especially the students, spend a lot of hours on the Internet. The excessive use of the Internet may lead to internet addiction, resulting in serious problems. It is necessary to recognize the associated factors with internet addiction. We found a significant relationship between internet addiction and general self-efficacy, difficulty in emotion regulation, and resilience so that these factors can predict internet addiction. Identifying at-risk students and training them with the necessary skills can reduce the prevalence of internet addiction.

\section{Introduction}

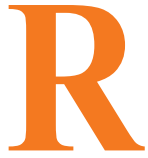

ecently, internet use has become an integral part of everyday life, especially among the youth. However, the excessive use of internet generates major public health problems, called "Internet Addiction" (IA) (cited by Jorgenson, Chih-Jui Hsiao, Yen, 2016). IA, as a mental and behavioral disorder, is characterized by the extreme use of internet by an individual. It manifests as a strong desire or craving to reuse the internet; moreover, withdrawal reactions are observable when the internet use is discontinued or reduced, which are accompanied by other biopsychological symptoms (American Psychiatric Association, 2013).

Based on previous research, the prevalence rate of IA has been assessed as $9.8-15.2 \%$ in the United States, $1.5-19.4 \%$ in Greece, $15.3 \%$ in Taiwan, and 2.6-14.9\% in South Korea (Lee, Shin, Cho, \& Shin, 2014). Furthermore, surveys in Iran revealed that almost more than half of the samples were afflicted with the IA or were at-risk for it (Ghaderi Rammazi, Askarizadeh, Ahmadi, and Divsalar, 2017).

Young (1998) believed it is necessary to observe at least 4 of the following symptoms for the diagnosis of IA: preoccupation with the internet; they need to use the internet by increasing the amount of time to obtain satisfaction; inability to restrain the use of internet; having a sense of irritability when trying to stop using the internet; using the internet as a way to escape from difficulties or to elevate the mood, and lying to family mem- bers or friends to hide the amount of internet penetration. According to various studies, there is a significant relationship between IA and pathological factors, such as anxiety, Obsessive-Compulsive Disorder (OCD), depression, substance, alcohol and tobacco use, Attention-Deficit/Hyperactivity Disorder (ADHD), sleeping problems, and high-risk sexual behaviors (Koukia, Mangoulia, \& Alexiou, 2014; Sung, Lee, Noh, Park, \& Ahn, 2013; Ghanbari, Amani, Namdari Pezhman, Bidi, Kareshki, 2012; Mazhari, 2012; Alavi, Maracy, Jannatifard, Eslami, \& Haghighi, 2010; Jafari \& Fatehizadeh, 2012; Khoshakhlagh \& Faramarzi, 2012; Ko, Yen, Yen, Chen, \& Chen, 2012).

Emotion regulation influences psychological well-being (Aldao, Jazaieri, Goldin, \& Gross, 2014). In addition, recent studies have reported difficulties in emotion regulation are associated with a tendency toward addiction and its predictability (EsmaliNasab, Andamikhoshk, Azarmi, samarrokhi, 2014). Furthermore, people with severe deficits in emotion regulation are more likely to use different substances (Wilens, Martelon, Anderson, Shelley-Abrahamson, Biederman, 2013). There are some common features between substance use disorders and IA. Studies revealed the odds of difficulties in emotion regulation or dysfunctional emotion regulation strategies are greater in students with severe IA (Mo, Chan, Chan, Lau, 2018; Spade \& Marino, 2017).

Mahapatraa \& Sharmab (2018) reported that people with alexithymia (i.e. characterized by the inability to recognize, express, and communicate emotions) might overuse internet as a strategy to regulate their emotions. Self-efficacy concept was defined by Bandura as the 
"beliefs of people about their ability" with a significant influence on the "cognitive, affective, motivational, and selection processes" (Bandura, 1993). Moreover, it is associated with life satisfaction, emotional health, decision making, as well as coping with stress and depression (Craparo et al., 2014). Despite the claims of prior research (Odaci, 2013), studies suggested no strong relationship between IA and self-efficacy (Craparo et al., 2014). However, others (İskender \& Akin, 2010) revealed a negative relationship between social selfefficacy and IA.

Resilience is also associated with IA as a protective factor (Robertson, Yan \& Rapoza, 2018). Resilience is defined as "a dynamic process wherein individuals display positive adaptation despite experiencing significant adversity or trauma" (Luthar \& Cicchetti, 2000). In addition to the relationship between resilience and IA (Zhou, Zhang, Liu, \& Wang, 2017), reports indicated an association between resilience and emotion regulation (Andamikhoshk, Golzar, \& Esmaeilinasab, 2013), and self-efficacy (Craparo et al., 2014).

As previously stated, IA is highly prevalent among students; thus, that has unpleasant consequences on their health. It was also reported from several research findings that emotion regulation, resilience, and self-efficiency majorly impact the pathology of a wide range of disorders, including IA. However, there are conflicting findings regarding the relationship between self-efficacy and IA. Furthermore, despite the importance of students' health as a decisive strata of society, few studies have been conducted in this area. Most existing studies have investigated a single variable, while most human behaviors are affected by several factors. Therefore, the present study aimed to explore whether resilience, self-efficacy, and emotion regulation can predict IA in students.

\section{Methods}

This was a descriptive study. The statistical population comprised all medical students affiliated to Shahid Beheshti University of Medical Sciences. The research sample consisted of 96 students, selected by random multistage cluster sampling method. In the first step of sampling, some classes were randomly selected. Also, all subjects received an explanation about the research purposes.

Difficulties in Emotion Regulation Scale: (Gratz \& Roemer, 2004). This 36-item tool is a multidimensional self-reporting tool with 6 subscales. In addition to assessing emotion regulation, it assesses the difficulty in emotion regulation. Higher scores indicate more serious difficulties in emotion regulation (Aminian, 2009). Questions $1,2,6,7,8,10,17,20,22,24$, and 34 have a reverse scorecard. The results of the reliability test (Gratz \& Roemer, 2004) revealed that this scale has a high internal consistency. Khanzadeh, Saidiyan, Hosseinchary, \& Edrissi (2012) investigated the psychometric properties of this scale in an Iranian sample; the internal consistency for all of its subscales was reported from 0.86 to 0.88 by the Cronbach's alpha coefficient. Furthermore, its subscales' test-retest coefficient ranged from 0.79 to 0.91. In the present study, the internal consistency was obtained as 0.81 by the Cronbach's alpha coefficient. We used the whole scale.

Self-Efficacy Scale: This scale was developed by Sherer and Adams (1983). It contains 17 items, each of which is answered on a five-point Likert-type scale, including (completely disagree: 1), (disagree: 2 ), (no idea: 3), (agree: 4), and (completely agree: 5). Items 2, 4, 5, 6, $7,10,11,12$, and 14 are scored in a reverse order. The maximum obtainable score is 85 and the minimum one is 17 . The reliability of this questionnaire was calculated as 0.82 (Saki, Nemati, \& Rezaei, 2015); in this study, this rate was obtained equal to 0.88 . Therefore, it can be applied in the Iranian population. Connor-Davidson Resilience Scale: This 25-item tool was developed by Corner and Davidson (2003). This scale has been standardized in Iran by Mohammadi (2005). The validity of this scale demonstrated coefficients ranging from 0.41 to 0.64 (Jowkar, 2007). The obtained Cronbach`s alpha coefficient in this study was equal to 0.76 .

Young's Internet Addiction Test (IAT): This scale was developed by Young (1988). The respondents answer to each of the 20 items on a five-point Likert-type scale. The test scores range from 0 to 100; higher scores indicate greater dependency on the internet. In an earlier study, Young et al., reported the internal reliability of the scale as 0.92 (Young, 1988; cited by Alavi Jannatifard, Maracy, \& Rezapour, 2010). In Iran, the Cronbach's alpha coefficient of this scale was assessed as 0.71 for its reliability. The discriminant and concurrent validities of the scale were assessed as 0.62 and 0.50 , respectively (Masoudnia, 2012). In this study, the Cronbach's alpha coefficient for the internal consistency of it was equal to 0.78 .

\section{Results}

Based on the results, from 96 students with the age of $19.73(1.11), 50(52.1 \%)$ subjects were male, and $46(47.9 \%)$ were female. According to the study partici- 
pants, more than half of them (64.8) had a 4-member family and their mother's educational level was under diploma 7(7.3), diploma 19(19.8), post-diploma 7(7.3), BS 31(32.3), MA. 22(22.9), and PhD. 10(10.4). The IA scores of $79(82.9 \%$ ) of the students were normal (below $50), 15(15.6 \%)$ were at risk for IA (50-79), and 2(2.1\%) were dependent on the internet (80-100). The mentioned cut-off points have been suggested by previous researches (e.g. Alavi et al., 2010). It indicates that only $17.7 \%$ of the students were either at the risk of addiction or dependence on the internet.

According to the obtained results, as shown in Table 1, there was a positive and significant relationship between the difficulties in emotion regulation and IA $(\mathrm{r}=0.321)$. That is, with increasing difficulty in the emotion regulation, the prevalence rates of addiction increase, and vice versa. There is a significant negative relationship between self-efficacy and resilience $(\mathrm{r}=-0.424, \mathrm{r}=-0.222)$. That is, with increasing difficulty in the emotion regulation, the rates of IA decrease. To predict IA, the independent variables (DER, GSE, Resilience) were introduced to stepwise regression analysis (for all questionnaires, the whole scale was used). By examining the matrix of correlation between the predicting variables, we can claim that the Collinearity assumption was observed; i.e. in line with other indices. The same was true for the other indicators like tolerance and variance inflation factor.

As per Table 2, Self-Efficacy (GSE) and difficulty in emotion regulation could predict 0.276 of the variance of IA in the samples. This rate is $25 \%$ if adjusting that to the real community $(\mathrm{R} 2=0.276, \mathrm{R} 2 \mathrm{adj}=0.257, \mathrm{P}<0.01)$. However, resilience poorly anticipates IA. Considering the standardized beta coefficients, under the control of other variables, per each unit of variation in standard coefficients, the dependent variable coefficient changes one standard deviation. According to the beta coefficients in Table 3, among independent variables, self-efficacy $(B=-$ $0.37 ; \mathrm{t}=-3.81)$ had a higher predictive value than difficulties in emotion regulation $(\mathrm{B}=0.27 ; \mathrm{t}=2.80)$.

\section{Discussion}

The obtained results suggested a significant multicorrelation between IA and self-efficacy and difficulty in emotion regulation. This finding is in line with the results of some studies (İskender \& Akin, 2010). However, the relationship between resilience and IA was not very strong. Its relationship with self-efficacy was strong and in line with the study of Sagonea \& Carolia (2013). Such finding might be due to the impact of resilience on IA which is more indirect, and this relation may be through self-efficacy.

In explaining the relationship between IA and self-efficacy, we could claim that those with high self-efficacy were more likely to be able to manage their tendencies; e.g. extensive internet use. The relationship between selfefficacy and emotion regulation may demonstrate such explanation (Jalali \& ahadi, 2016). Regarding the relationship between IA and difficulties with emotional reg-

Table 1. Statistical description and the matrix correlation of the research variables

\begin{tabular}{|c|c|c|c|c|}
\hline Variables & Mean \pm SD & IA & DER & GSE \\
\hline 1. IA & $43.14 \pm 12.32$ & 1 & & \\
\hline 2. Difficult in Emotion Regulation (DER) & $95.49 \pm 13$ & $0.321^{*}$ & 1 & \\
\hline 3. General Self-Efficacy (GSE) & $61.14 \pm 7.1$ & $-0.424^{*}$ & -0.173 & 1 \\
\hline 4. Resilience & $67.00 \pm 12.06$ & $-0.222^{* *}$ & $-0.267^{*}$ & $0.570^{*}$ \\
\hline
\end{tabular}

Table 2. Model summary of stepwise regression analysis

\begin{tabular}{|c|c|c|c|c|c|c|c|c|c|}
\hline \multirow{2}{*}{ Model } & \multirow{2}{*}{$\mathbf{R}$} & \multirow{2}{*}{$\begin{array}{c}\mathbf{R} \\
\text { Square }\end{array}$} & \multirow{2}{*}{$\begin{array}{l}\text { Adjusted R } \\
\text { Square }\end{array}$} & \multirow{2}{*}{$\begin{array}{l}\text { Std. Error of } \\
\text { the Estimate }\end{array}$} & \multicolumn{5}{|c|}{ Change Statistics } \\
\hline & & & & & R Square Change & F Change & df 1 & df 2 & Sig F Change \\
\hline GSE & 0.451 & 0.203 & 0.193 & 11.07426 & 0.203 & 20.410 & 1 & 80 & 0.000 \\
\hline DER & 0.525 & 0.276 & 0.257 & 10.62694 & 0.072 & 7.877 & 1 & 79 & 0.006 \\
\hline
\end{tabular}


Table 3. The analysis of IA regression based on GSE, DER, and resilience

\begin{tabular}{|c|c|c|c|c|c|c|c|c|}
\hline \multirow{2}{*}{ Step } & \multirow{2}{*}{ Predicting Variables } & \multicolumn{3}{|c|}{ B } & \multirow{2}{*}{$\mathbf{t}$} & \multirow{2}{*}{ Sig. } & \multirow{2}{*}{ Tolerance } & \multirow{2}{*}{ VIF } \\
\hline & & USC & SE & SC & & & & \\
\hline 1 & GSE & -0.654 & 0.171 & -0.379 & -3.817 & 0.000 & 0.932 & 1.072 \\
\hline 2 & DER & 0.264 & 0.094 & 0.278 & 2.807 & 0.006 & 0.932 & 1.072 \\
\hline
\end{tabular}

ulation, we can refer to Kober (2014). Kober suggested that emotion regulation is a causal factor in substance use disorders of adolescence. Moreover, more considerable difficulties in emotion regulation are related to excessive drug use as a means of emotion regulation (Bonn-Miller, Vujanivic, \& Zvolensky, 2008). Therefore, the strong desire to reuse internet is a type of emotion regulation. This explanation is consistent with Akbari (2017), Mo et al., (2018), Spade \& Marino (2017), and Mahapatraa \& Sharmab (2018) investigations.

There was also a negative relationship between the resiliency and IA. Studies have suggested that individuals with limited ability to understand their own and others' emotions were less able to cope with stress and crises; thus, they demonstrate more behavioral problems (Zarei \& Asadi, 2011). Moreover, the study findings revealed a positive association between suppression and depressive symptoms (Larsen et al., 2013). Therefore, emotional regulation strategies can directly affect IA; moreover, they indirectly impact maladaptive emotional regulation strategies associated with mental disorders that may negatively influence behavioral management. Furthermore, IA is highly related to depression, anxiety, ADHD, and substance use disorders (Jorgenson et al., 2016; Li, Hou, Yang, Jian, \& Wang, 2019). Another finding of this study was the severity of medical students' dependence on the internet.

Data analysis indicated a low prevalence of IA in medical students, compared to other medical sciences students (Ghaderi Rammazi et al., 2017; Doosti Irani, Bagheri Amiri, Khajehkazemi, Mostafavi, 2017). This might be because medical students may not have much time for internet use; or because they have enough information about health problems and self-care to be aware of the proper use of it.

Internet use is increasing and recognized among the most essential means of accessing information. Furthermore, young people, especially students, have to spend many hours on the internet; thus, it is possible to improve emotion regulation caused by education. As a result, it may prevent the destructive effects of this new communication technology. Prior research on emotion regulation training in terms of substance use disorders has suggested the effectiveness of this intervention (Ahmadi, Sohrabi, \& Borjali, 2018; Choopan, et al., 2016); therefore, emotion regulation could be beneficial in IA.

The limitations of the present study included the following: this research was limited to Shahid Beheshti University of Medical Sciences and conducted on medical students only; therefore, caution should be taken in the generalization of the findings. Moreover, we applied self-reporting tools for data collection. As a result, there might be possible biases; e.g. some subjects might have not had a proper insight into what the self-assessment tool measures. Internet use is increasing, and it is recognized among the most important means of accessing information; therefore, young people, and especially the student population, have to spend hours on the internet.

The obtained results suggested that although IA is less prevalent among medical students, it can be influenced by factors like emotion regulation strategies and selfefficacy. Therefore, emotion regulation skills training is suggested for this group. Such measures may prevent the destructive effects of this new communication technology and reduce the level of IA.

\section{Ethical Considerations}

\section{Compliance with ethical guidelines}

All ethical principles were considered in this article. The study participants were informed about the purpose of the research and its implementation stages. They were also assured about the confidentiality of their information. Moreover, they were allowed to discontinue participation in the study whenever they wish. Eventually, if desired, the results of the research would be available to them. 


\section{Funding}

This research did not receive any specific grant from funding agencies in the public, commercial, or not-forprofit sectors.

\section{Authors' contributions}

All authors contributed in preparing this article.

\section{Conflict of interest}

All authors certify that this manuscript has neither been published in whole, nor in part, or being considered for publication elsewhere. The authors have no conflicts of interests to declare.

\section{References}

Ahmadi, G., Sohrabe, F., borjali, A. (2018). [Effectiveness of emotion regulation training on reappraisal and emotional suppression in soldiers with opioid use disorder (Persian)]. Counseling Culture and Psycotherapy, 9(34), 191-209.

Akbari, M. (2017). Metacognitions or distress intolerance: The mediating role in the relationship between emotional dysregulation and problematic internet use. Addictive Behaviors Reports, 6, 128-33. [DOI:10.1016/j.abrep.2017.10.004] [PMID] [PMCID]

Alavi, S. S., Maracy, M. R., Jannatifard, F., Eslami, M., \& Haghighi, M. (2010). [A survey of relationship between psychiatric symptoms and internet addiction in students of Isfahan Universities (Persian)]. Avicenna Journal of Clinical Medicine, 17(2), 57-65.

Aldao, A., Jazaieri, H., Goldin, P. R., \& Gross, J. J. (2014). Adaptive and maladaptive emotion regulation strategies: Interactive effects during CBT for social anxiety disorder. Journal of Anxiety Disorders, 28(4), 382-9. [DOI:10.1016/j.janxdis.2014.03.005] [PMID] [PMCID]

American Psychiatric Association. (2013). Diagnostic And Statistical Manual of Mental Disorders (DSM-5®). Washington American Psychiatric Association. [DOI:10.1176/appi books.9780890425596]

Aminian, M. (2009). [The relationship between emotion regulation, negative events of life and body image with nutritional disorders in female in Ahwaz (Persian)] [MSc. Thesis]. Ahvaz: Islamic Azad University of Ahvaz.

Andamikhoshk, A., Golzar, M., \& Esmaeilinasab, M. (2013). Role of nine strategies of cognitive emotion regulation in the prediction of resilience. Journal of Behavior Therapy and Experimental Psychiatry, 7, 57-66.

Bandura, A. (1993). Perceived self-efficacy in cognitive development and functioning. Educational Psychologist, 28(2),117-48.
Bonn-Miller, M. O., Vujanovic, A. A., \& Zvolensky, M. J. (2008). Emotional dysregulation: Association with coping-oriented marijuana use motives among current marijuana users. Substance Use $\mathcal{E}$ Misuse, 43(11), 1653-65. [DOI:10.1080/10826080802241292] [PMID]

Choopan, H., Kalantarkousheh, S., Aazami, Y., Doostian, Y., Farhudian, A., \& Massah, O. (2016). Effectiveness of emotion regulation training on the reduction of craving in drug abusers. Addiction and Health, 8(2), 68-75.

Connor, K. M., \& Davidson, J. R. (2003). Development of a new resilience scale: The Connor-Davidson Resilience Scale (CDRISC). Depression and Anxiety, 18(2), 76-82. [DOI:10.1002/ da.10113] [PMID]

Craparo, G., Messina, R., Severino, S., Fasciano, S., Cannella, V., Gori, A., et al., (2014). The relationships between self-efficacy, internet addiction and shame. Indian Journal of Psychological Medicine, 36(3), 304-7. [DOI:10.4103/0253-7176.135386] [PMID] [PMCID]

Doosti Irani, A., Bagheri Amiri, F., Khajehkazemi, R., \& Mostafavi, E. (2017). [Prevalence of internet addiction among students and graduates of epidemiology, clinical sciences, and basic sciences in Iran: A cross-sectional study (Persian)]. Iranian Journal of Epidemiology, 13(1), 14-21.

EsmaliNasab, M.; Andami Khoshk, A.; Azarmi, H.; Samar Rakhi, A. (2014). The predicting role of difficulties in emotion regulation and distress tolerance in students' addiction potential. Journal of Research on Addiction, 29(8), 49-64.

Ghaderi Rammazi, M., Askarizadeh, G., Ahmadi, G., \& Divsalar, K. (2018). The role of psychiatric symptoms, social support and meaning in life in predicting internet addiction among university students: A causal model. Practice in Clinical Psychology, 6(2), 101-10. [DOI:10.29252/nirp.jpcp.6.2.101]

Ghanbari, S., Amani, A., Namdari Pezhman, M., Bidi, F., Kareshki, H. (2012). [Structural analysis of relationship of internet addiction with depression, social adjustment and self-esteem (Persian)]. Avicenna Journal of Clinical Medicine, 19(3), 41-8.

Gratz, K. L., \& Roemer, L. (2004). Multidimensional assessment of emotion regulation and dysregulation: Development, factor structure, and initial validation of the difficulties in emotion regulation scale. Journal of Psychopathology and Behavioral Assessment, 26(1), 41-54. [DOI:10.1023/ B:JOBA.0000007455.08539.94]

İskender, M., \& Akin, A. (2010). Social self-efficacy, academic locus of control, and internet addiction. Computers $\mathcal{E}$ Education 54(4), 1101-6. [DOI:10.1016/j.compedu.2009.10.014]

Jafari, N., \& Fatehizadeh, M. (2012). [Investigation of the relationship between internet addiction and depression, anxiety, stress and social phobia among students in Isfahan University (Persian)]. Scientific Journal of Kurdistan University of Medical Sciences, 17(4), 1-9.

Jalali, A; Ahadi, H. (2016). [On the relationship of cognitive emotion regulation, self-efficacy, impulsiveness, and social skills with substance abuse in adolescents (Persian)]. Journal of Research on Addiction, 9(36), 77-8.

Jorgenson, A. G., Hsiao, R. C. J., \& Yen, C. F. (2016). Internet addiction and other behavioral addictions. Child and Adolescent Psychiatric Clinics, 25(3), 509-20. [DOI:10.1016/j. chc.2016.03.004] [PMID] 
Jowkar, B. (2007). [The mediating role of resilience in the relationship between general and emotional intelligence and life satisfaction (Persian)]. Contemporary Psychology, 2(4), 3-12.

Khanzadeh, M., Saeediyan, M., Hosseinchari, M., \& Edrissi, F. (2012). [Factor structure and psychometric properties of difficulties in emotional regulation scale (Persian)]. International Journal of Behavioral Sciences, 6(1), 87-96.

Khoshakhlagh, H., \& Faramarzi, S. (2012). The relationship of emotional intelligence and mental disorders with internet addiction in internet users university students. Addiction $\mathcal{E}$ health, 4(3-4), 133-41. [PMID] [PMCID]

Ko, C. H., Yen, J. Y., Yen, C. F., Chen, C. S., \& Chen, C. C. (2012). The association between Internet addiction and psychiatric disorder: A review of the literature. European Psychiatry, 27(1), 1-8. [DOI:10.1016/j.eurpsy.2010.04.011] [PMID]

Kober, K. (2014). Emotion regulation in Substance Use Disorders. In J. J. Gross (Ed), Handbook of emotion regulation $\left(2^{\text {nd }} \mathrm{ed}\right.$. (pp. 428-446). New York, NY: Guilford.

Koukia, E., Mangoulia, P., \& Alexiou, E. (2014). Internet Addiction and Psychopathological Symptoms in Greek University Students. Journal of Addictive Behaviors, Therapy \& Rehabilitation, 3, 3. [DOI:10.4172/2324-9005.1000125]

Larsen, J. K., Vermulst, A. A., Geenen, R., Van Middendorp, H. English, T., Gross, J. J., et al., (2013). Emotion regulation in adolescence: A prospective study of expressive suppression and depressive symptoms. The Journal of Early Adolescence, 33(2), 184-200. [DOI:10.1177/0272431611432712]

Lee, J. Y., Shin, K. M., Cho, S.-M., \& Shin, Y. M. (2014). Psychosocial risk factors associated with internet addiction in Korea. Psychiatry Investigation, 11(4), 380-6. [DOI:10.4306/ pi.2014.11.4.380] [PMID] [PMCID]

Li, G., Hou, G., Yang, D., Jian, H., \& Wang, W. (2019). Relationship between anxiety, depression, sex, obesity, and internet addiction in Chinese adolescents: A short-term longitudinal study. Addictive Behaviors, 90, 421-7. [DOI:10.1016/j.addbeh.2018.12.009] [PMID]

Luthar, S. S., \& Cicchetti, D. (2000). The construct of resilience Implications for interventions and social policies. Development and Psychopathology, 12(4), 857-85. [DOI:10.1017/ S0954579400004156] [PMCID]

Mahapatra, A., \& Sharma, P. (2018). Association of internet addiction and alexithymia- A scoping review. Addictive Behaviors, 81, 175-82. [DOI:10.1016/j.addbeh.2018.02.004] [PMID]

Masoudnia, E. (2012). Internet addiction and risk of sleep disorder among adolescents. Journal of Research in Behavioural Sciences, 10(5), 350-62. [DOI: 10.18869/nrip.irj.15.2.141]

Mazhari, S. (2012). The prevalence of problematic internet use and the related factors in medical students, Kerman, Iran. Addiction \& Health, 4(3-4), 87-94. [PMID] [PMCID]

Mo, P. K., Chan, V. W., Chan, S. W., \& Lau, J. T. (2018). The role of social support on emotion dysregulation and internet addiction among Chinese adolescents: A structural equation model. Addictive Behaviors, 82, 86-93. [DOI:10.1016/j.addbeh.2018.01.027] [PMID]

Mohammadi, M. (2005). [The effective factors on resistance in the people with risk of subectance abuse (Persian) [PhD. disserta- tion]]. Tehran: University of Social Welfare and Rehabilitation Sciences.

Odac1, H. (2013). Risk-taking behavior and academic self-efficacy as variables accounting for problematic internet use in adolescent university students. Children and Youth Services Review, 35(1), 183-7. [DOI:10.1016/j.childyouth.2012.09.011]

Robertson, T. W., Yan, Z., \& Rapoza, K. A. (2018). Is resilience a protective factor of internet addiction? Computers in Human Behavior, 78, 255-60. [DOI:10.1016/j.chb.2017.09.027]

Sagone, E., \& De Caroli, M. E. (2013). Relationships between resilience, self-efficacy, and thinking styles in Italian middle adolescents. Procedia-Social and Behavioral Sciences, 92, 838-45. [DOI:10.1016/j.sbspro.2013.08.763]

Saki, R., Nematti, H., \& Rezaei, M. (2015). Investigation of the relationship between self-efficacy and empowerment in comparison with job performance among the state high school female teachers in Tehran (Persian)]. Research in Medical Education, 1(5), 32-51.

Sherer, M., \& Adams, C. H. (1983). Construct validation of the self-efficacy scale. Psychological Reports, 53(3), 899-902. [DOI:10.2466/pr0.1983.53.3.899]

Spada, M. M., \& Marino, C. (2017). Metacognitions and emotion regulation as predictors of problematic internet use in adolescents. Clinical Neuropsychiatry, 14(1), 59-63. [DOI:10.1016/j. abrep.2017.10.004]

Sung, J., Lee, J., Noh, H. M., Park, Y. S., \& Ahn, E. J. (2013). Associations between the risk of internet addiction and problem behaviors among Korean adolescents. Korean Journal of Family Medicine, 34(2), 115-22. [DOI:10.4082/kjfm.2013.34.2.115] [PMID] [PMCID]

Wilens, T. E., Martelon, M., Anderson, J. P., Shelley-Abrahamson, R., \& Biederman, J. (2013). Difficulties in emotional regulation and substance use disorders: A controlled family study of bipolar adolescents. Drug and Alcohol Dependence, 132(1-2), 114-21. [DOI:10.1016/j.drugalcdep.2013.01.015] [PMID] [PMCID]

Young, K. S. (1998). Caught in the net: How to recognize the signs of internet addiction-and a winning strategy for recovery. Hoboken: John Wiley \& Sons.

Zarei, S., Asadi, Z. (2011). [Comparison of personality traits and coping styles in addicted and normal adolescents (Persian)]. Research on Addiction, 5(20), 87-104.

Zhou, P., Zhang, C., Liu, J., \& Wang, Z. (2017). The relationship between resilience and Internet addiction: A multiple mediation model through peer relationship and depression Cyberpsychology, Behavior, and Social Networking, 20(10), 634-9. [DOI:10.1089/cyber.2017.0319] [PMID] 
This Page Intentionally Left Blank 